\title{
ANTONIO CANDIDO LEITOR DE MARCEL PROUST: OU O REALISMO COMO TEORIA LITERÁRIA ${ }^{1}$
}

http://dx.doi.org/10.11606/issn.2237-1184.v0i29p241-262

Ronaldo Tadeu de Souza

Universidade de São Paulo (USP)

RESUM0

O presente artigo tem como objetivo interpretar a leitura empreendida por Antonio Candido daquele que para muitos foi seu escritor preferido, o francês Marcel Proust. Com o ensaio "Realidade e realismo" (via Proust) nosso crítico a partir do autor do Em busca do tempo perdido nos oferece uma modalidade sugestiva e singular de realismo enquanto teoria literária.

\section{ABSTRACT}

This article aims to interpret the reading undertaken by Antonio Candido of that one who for many was his favorite writer, the Frenchman Marcel Proust. With the essay "Reality and Realism" (via Proust) our critic from the author of In Search of Lost Time offers us a suggestive and singular modality of realism as a literary theory.

\section{PALAVRAS-CHAVE:}

Antonio Candido;

Marcel Proust;

romance;

realismo;

teoria literária.

\section{KEYWORDS}

Antonio Candido;

Marcel Proust;

novel;

realism;

literary theory.

\footnotetext{
${ }^{1}$ Este artigo resulta de um trabalho apresentado no Seminário Antonio Candido 100 Anos realizado na Faculdade de Filosofia, Letras e Ciências Humanas da Universidade de São Paulo nos dias 10 a 13 de setembro de 2018 e que foi organizado pelo grupo de pesquisa Articulação Discente para Pensamento Social Brasileiro e o departamento de sociologia, ambos da Universidade de São Paulo-USP. Agradeço aos organizadores do evento a oportunidade de expor o texto, aos comentários do professor Alex Moura do departamento de filosofia da USP e as observações de Rebeca Errázuriz da Universidade Adolfo Ibánez do Chile e de Ivo Soares Paulino do departamento de sociologia da USP. Agradeço imensamente aos pareceristas anônimos. As imperfeições que permaneceram são de minha responsabilidade.
} 


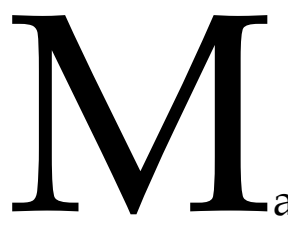

arcel Proust, autor do monumental Em busca do tempo perdido, uma das maiores obras do modernismo literário do século XX, junto com Ulisses de James Joyce, O processo e O castelo de Franz Kafka e Mrs. Dalloway de Virginia Woolf, mereceu a atenção dos maiores críticos literários e teóricos da estética no século XX. Dentre os primeiros estão, Roland Barthes, Walter Benjamin, George Lukács e Erich Auerbach; e entre os segundos constam Theodor Adorno, Gilles Deleuze, Derwent May, Paul de Man e George Poulet. Como país que forjou ao longo do tempo importante tradição de crítica e teoria literária desde os escritos de Sílvio Romero até a consolidação dos departamentos de teoria literária e literatura comparada, que irradiaram-se virtuosamente a partir da Universidade de São Paulo, no fim do século passado, nossa aproximação ao escritor francês não seria diferente daquela em que os referidos críticos e teóricos estavam envolvidos. ${ }^{2}$ Em artigo publicado no Suplemento Mais! do jornal Folha de São Paulo de 07/07/2002, a professora Walnice Nogueira Galvão, afirmou que "o Brasil [...] foi fértil solo para estudos proustianos". ${ }^{3}$ Ela segue afirmando que, "lia-se muito Marcel Proust, e seus livros, obrigatoriamente importados encontravam acolhida". ${ }^{4}$ Entre nós, nosso maior crítico literário, Antonio Candido de Melo e Souza vivendo em ambiente cultural no qual Em busca do tempo perdido era leitura quase que obrigatória, também dedicou, assim como seus pares internacionais (Benjamin, Auerbach, Deleuze, Barthes, May), sua crítica literária a Marcel Proust. (Ressalte-se neste aspecto que a obra de Proust foi publicada pela editora Globo de Porto Alegre, tal como o Balzac de Paulo Rónai, nos anos 1940, e que teve no projeto de tradução nomes de nossa alta literatura como Mário Quintana, Manuel Bandeira, Carlos Drummond de Andrade e Lúcia Miguel Pereira.) Seguindo ainda a professora Walnice Nogueira Galvão, “Antonio Candido foi um proustiano de vida inteira" 5 - e dedicou um ensaio, junto com outras

\footnotetext{
2 Ainda são necessários estudos que problematizem o estilo de recepção de um autor como Marcel Proust e a singularidade de sua obra maior num país periférico como o Brasil e que construiu ao longo do tempo histórico e cultural um sistema literário consistente e significativo enquanto narrativa, enredo e estética.

${ }^{3}$ GALVÃO, Walnice Nogueira. Novos caminhos de Proust. Suplemento Mais! Folha de São Paulo, 07 de julho de 2002.

4 Idem, ibidem.

${ }^{5}$ GALVÃO, Walnice Nogueira. Novos caminhos de Proust. Suplemento Mais! Folha de São Paulo, 07 de julho de 2002.
} 
resenhas ao escritor francês. A saber, Realidade e realismo (via Marcel Proust) consta como uma das contribuições de nosso crítico à fortuna interpretativa sobre Proust e sua obra. Neste contexto de centenário de Antonio Candido, com efeito, é sugestivo averiguarmos o que sua interpretação deste escritor maior nos diz. O presente artigo tem o singelo objetivo de apresentar, de modo reconstrutivo e estilizado, o ensaio Realidade e realismo (via Marcel Proust) de Antonio Candido. Com isto pretendo, além deste objetivo, argumentar que o realismo tal como o crítico o entendeu a partir de Proust, pode ser uma forma imaginativa de teoria literária (ao contrário de certos reducionismos de alguns textos de George Lukács, o teórico da realidade plasmada na literatura). Os textos mobilizados para a presente interpretação, além do já citado ensaio de Antonio Candido Realidade e realismo (via Marcel Proust), serão O realismo crítico hoje de George Lukács e alguns breves comentários de A passagem do três ao um de Leopoldo Waizbort em que o tema do "realismo" referenciado a partir de Proust em Antonio Candido é, significativamente, explorado.

Com meus objetivos delineados, o artigo apresenta três andamentos: no primeiro, discute-se a recepção de Marcel Proust no Brasil; no segundo andamento, apresento brevemente dois textos de Antonio Candido sobre Proust antes da publicação do ensaio Realidade e realismo (via Marcel Proust) de 1993, os textos são de 1943 e 1958 publicados respectivamente nos jornais Folha da Manhã e O Estado de São Paulo; no terceiro andamento comento e analiso o referido ensaio de nosso crítico sobre o Em busca do tempo perdido tendo como referência oposta o realismo documental e plano de George Lukács presente em seu livro O realismo crítico hoje. Deste modo, pretendo expor o realismo de Antonio Candido como teoria literária possível.

\section{Um país de proustianos...}

Não é possível propor qualquer consideração acerca da cultura literária em torno do Em busca do tempo perdido de Marcel Proust desde as primeiras edições do romance na França do começo do século para alémfronteira do país do escritor. (Hoje, sem dúvida, No caminho de Swann e os outros seis volumes - a depender da edição - que compõem a obra são lidos com prazer sublime por proustianos em todo mundo.) Entretanto, o Brasil foi sem dúvida ${ }^{6}$ um dos países que logo após Proust publicar as primeiras edições de seu livro passaram a ler o romance. Os volumes

\footnotetext{
${ }^{6}$ Na Alemanha Marcel Proust também mereceu acolhida por parte dos eruditos e da crítica literária, autores como Walter Benjamin e Erich Auerbach logo nos primeiro momento leram e comentaram o Em Busca do Tempo Perdido. Ver sobre isso: KAHN, Robert - Benjamin leitor de Proust. Alea, v. 14/1, 2012.
} 
iniciais chegaram ao Brasil em 1920. De acordo com a pesquisa de Maria Marta Laus Pereira de Oliveira, À sombra das raparigas em flor chega a Belo Horizonte na livraria Francisco Alves7; os cinco exemplares que aqui vieram foram disputados por jovens intelectuais e escritores do período entre eles, além de Carlos Drummond de Andrade estavam estes, Eduardo Frieiro, Milton Campos, Pedro Nava e Alberto Campos. ${ }^{8}$ Com o passar dos anos Marcel Proust tornou-se autor frequentado pelo público culto brasileiro. ${ }^{9}$ Ora, era mais do que natural que as inovações narrativas do Em busca... iriam chamar a atenção em meio intelectual que buscava, incessantemente, (re)construir sua cultura a partir da experiência modernista. Graça Aranha, um dos organizadores e porta-vozes da Semana de Arte Moderna de 1922 em São Paulo foi um dos primeiros críticos a publicar um artigo sobre Proust. ${ }^{10}$ De extensão curta, porém densa11 e complexa - Graça Aranha chamava a atenção dos leitores sobre a "sensibilidade extrema, [a] fragmentação da vida, [e a] decomposição do pensamento" 12 presentes no romance proustiano. ${ }^{13} \mathrm{E}$ desde então Em busca... fez parte de um conjunto de autores lidos, estudados, pesquisados e debatidos pelo público leitor (culto) e a crítica literária de jornal e especializada (nas universidades) no Brasil. As expressões de leituras proustianas, com efeito, se sucederam ao longo do tempo; em 1947 no Rio de Janeiro é fundado o Proust Club do Brasil de leitores amadores do escritor e anos antes, em 1941, Ruy Coelho, que havia obtido recentemente o diploma de filosofia e ciências sociais pela Universidade de São Paulo publica um dos primeiros textos de crítica literária sobre a obra de Proust para a revista Clima. O país de proustianos não mais parou de dedicar significativo espaço cultural e ensaístico ao autor do Em busca do tempo Perdido. E a crítica da crítica, o comentário do comentário, a nota de literatura da nota de literatura foram estabelecendo sucessivas e diversas posturas sensíveis e de interpretação diante do romance de Marcel Proust.

Roger Bastide, professor de ciências sociais da USP das primeiras gerações do curso, não se furtou a fazer parte da nação de proustianos.

\footnotetext{
7 OLIVEIRA, Maria Marta L. P. Aspects de la critique proustiene en France et au Brésil. Fragmentos, n. 2, v. 6, 1997, p. 69.

${ }^{8}$ De acordo com alguns críticos, como a própria Maria Marta Laus Pereira de Oliveira, Walnice Nogueira Galvão e Ione Andrade, já em 1919 em Maceió, Jorge de Lima recebe de um piloto de avião francês - que ao fazer escala na cidade vindo da Europa trazia as novidades parisienses para o poeta e médico - o segundo volume do Em busca do tempo perdido recém publicado.

${ }^{9}$ GALVÃO, Walnice Nogueira. Op. cit., p. 16.

${ }^{10}$ OLIVEIRA, Maria Mara L. P. Op. cit., p. 71.

${ }^{11}$ Idem, ibidem, p. 71.

${ }^{12} I d ., i b ., i b$.

${ }^{13}$ Malgrado as restrições de Graça Aranha ao aspecto excessivamente emocional do romance, característico do espírito Frances, ele não deixa de "reconhecer o estilo sensível de Proust". In: OLIVEIRA, Maria Mara L. P. Op. cit.
} 
Assim, em 1944, Bastide escreve "artigo intitulado 'Diálogo a uma voz: Marcel Proust'", em que um dos intuitos é comentar o texto de Ruy Coelho publicado três anos antes. ${ }^{14}$ As décadas seguintes continuaram a tradição de crítica proustiana iniciada por Graça Aranha, Jorge de Lima, Tristão de Athayde, Ruy Coelho e Roger Bastide. De modo que no percurso de conformação da cultura modernista brasileira:

o escritor francês torna-se, com efeito, uma espécie de ponto de passagem obrigatório para todos aqueles sejam cronistas ou críticos, que escrev[iam] nos jornais; e podemos citar alguns, talvez aqueles mais conhecidos hoje [do público acadêmico]: [...] Sérgio Buarque de Holanda (1948), Lúcia Miguel Pereira (1948), Augusto Meyer (1948), Raquel de Queiroz (1949), [...] Álvaro Lins (1952). ${ }^{15}$

Dois eventos foram fundamentais na formação do país de proustianos. Ainda na década de 1940 a nação de leitores de Proust pode ler o Em busca... no seu próprio idioma. É que "a editora Globo de Porto Alegre"16, reunindo alguns dos mais importantes escritores da época verteu para o português todos os volumes que compunham o romance. Deste modo, "Mario Quintana" traduziu No caminho de Swann, Às sombras das raparigas em flor, $O$ caminho de Guermantes e Sodoma e Gomorra; "Manuel Bandeira", ficou com a tarefa de traduzir "o quinto volume, $A$ prisioneira"; "A fugitiva", o sexto volume foi traduzido por Carlos Drummond de Andrade; e o sétimo e último volume, $O$ tempo redescoberto ficou sob a incumbência de "Lúcia Miguel Pereira". ${ }^{17}$ (A décima terceira edição, neste último volume, apresenta dois ensaios críticos ao seu final de duas proustianas brasileiras - a filósofa Olgária Matos ${ }^{18}$, que no texto Traduzir Proust disse que "o poeta-tradutor não pretende objetividade. [Ele] encontra uma harmonia entre as línguas [no caso a francesa e a portuguesa], na maneira pela qual roça o sentido-sentido que só pode ser tocado pela brisa da língua"19 e a teórica da literatura Leda Tenório da Motta, no seu ensaio A história de um texto, pode afirmar sobre o Recherche que ele mais do que qualquer outra obra literária expressou "[a] obsessão [de seu autor] de escrever um romance [...] onde passado e presente se

\footnotetext{
14 SILVA, Guilherme Ignácio. Prefácio. In: ALMEIDA, Alexandre Bebiano e WILLEMART, Philipe (orgs.) Proust 2011. São Paulo. Humanitas/FAPESP, 2012, p. 146.

15 ALMEIDA, Alexandre Bebiano. Um Proust mal lido, mas vivo? Nota sobre a recepção do romance proustiano nos decênios de 40 e 50. Lettres Françaises, n. 14, v. 2, 2013 pp. 277 e 278.

${ }^{16}$ GALVẪ, Walnice Nogueira. Op. cit., p. 16.

${ }^{17}$ Idem, ibidem, ibidem.

18 A cultura filosófica brasileira foi e é, também, leitora de Marcel Proust. Além de Olgária Matos, os filósofos Franklin Leopoldo e Silva, Carlos Nelson Coutinho e a filósofa Jeanne Marie Gagnebin dedicaram textos e ensaios ao escritor francês.

${ }^{19}$ MATOS, Olgária Chain Féres. Traduzir Proust. In: PROUST, Marcel. O tempo redescoberto, v. 7. Porto Alegre. Globo, 1998, p. 294.
} 
superpõem, confundindo a posição enunciativa e com ela os quartos [e os quadros] todos de uma vida".$^{20}$ ) O outro evento foi a publicação em 1950 do livro Proustiana brasileira. Editado sob a coordenação de Saldanha Coelho ${ }^{21}$ o trabalho reuniu os artigos anteriormente escritos por críticos e leitores brasileiros sobre o Em busca do tempo perdido: com isto, o livro empreendeu a organização (num único volume) da fortuna crítica no país sobre Marcel Proust até aquele momento.

Com a combinação de profissionalização, especialização e excesso de produção nos estudos de pós-graduação ocorreu que o francês nas universidades tornou-se "instrumental".22 Articulado com o fenômeno de "encerramento da língua francesa no secundário [nosso atual Ensino Médio]" 23 e a transformação do inglês em língua franca, os estudos (e, provavelmente, os leitores) de Proust "foram minguando". ${ }^{24}$ Contudo, mesmo assentada esta fase - o Brasil nunca deixou de ser solo "fértil para estudos" 25 sobre Marcel Proust. O país de proustianos conheceria ainda sucessivas traduções e reedições, novas edições e projetos editoriais sobre o Em busca do tempo perdido. Conheceria, também, dois acontecimentos intelectuais de valioso significado, fundamentais por assim dizer, para constituição da cultura literária em torno do escritor francês entre nós. $\mathrm{O}$ primeiro acontecimento foi a tese de doutoramento de Maria Marta Laus Pereira de Oliveira; defendida na Universidade Federal do Rio Grande do Sul em 1993 o trabalho - uma referência notável para os pesquisadores de Proust e sua recepção crítica entre nós - reconstruiu, acessando "vasto material" 26, a acolhida brasileira do Em busca... nas primeiras décadas do século passado. $O$ segundo acontecimento, imprescindível para a continuidade do país de proustianos, foi o Proust 2011. Embora realizado no Brasil, o Proust 2011, reuniu pesquisadores da Itália, Estados Unidos, Escócia e França para discutir a obra proustiana no contexto do projeto de pesquisa BREPOLS-FAPESP. Institucionalmente, o projeto foi desenvolvido pelo CNRS, a Equipe Proust do Institut des Manuscrits Modernes de Paris e a Universidade de São Paulo (especialmente aqui, a figura do proustiano Philipe Willemart, foi decisiva na coordenação do projeto). No Proust 2011: "a pluralidade de leituras" 27 caracterizou o aspecto distintivo

\footnotetext{
${ }^{20}$ MOTTA, Leda Tenório da. A história de um texto. In: PROUST, Marcel. O tempo redescoberto, v. 7. Porto Alegre. Globo, 1998, pp. 299, 302 e 303.

21 WILLEMART, Philipe. Abertura do Congresso Proust 2011. In: ALMEIDA, Alexandre Bebiano e WILLEMART, Philipe (orgs.) Proust 2011. São Paulo: Humanitas/FAPESP, 2012, p. 18.

${ }^{22}$ GALVÃO, Walnice Nogueira. Op. cit., p. 17.

${ }^{23} \mathrm{Idem}$, ibidem, ibidem.

${ }^{24} I d ., i b ., i b$.

${ }^{25} I d ., i b .$, p. 17.

${ }^{26}$ ALMEIDA, Alexandre Bebiano. Op. cit., p. 278.

27 SILVA, Guilherme Ignácio. Op. cit., p. 8.
} 
do encontro. Ora, Antonio Candido, nosso maior crítico literário, esteve entre os primeiros leitores de Proust nos "anos 1930 aos [19]60" 28 e foi lembrado por Philipe Willemart no Proust 2011 como um dos "críticos importantes" da obra do autor de o Em busca do tempo perdido "que não puderam"29 participar do encontro. Assim, num ambiente que frequentava Marcel Proust, e na medida em que Antonio Candido sempre esteve atente às questões artísticas, literárias e morais da sociedade brasileira, era natural que nosso crítico influenciado por essas constelações da experiência dedicasse seu olhar ao autor do Em busca do tempo perdido. Suas posições comentando Proust apresentam três momentos: o contato inicial com a obra (1943), demonstrando restrições pelo traço excessivamente emocional do romance, a concordância com a biografia do ensaísta inglês George Painter (texto escrito em 1958), na qual se entrelaçam os sentimentos literários com as circunstâncias afetivas da vida verdadeira e a crítica literária presente em Realidade $e$ realismo (via Marcel Proust), que de certo modo ${ }^{30}$ é a sequência deste texto de 1958 sobre a biografia de Painter, pois neste ensaio lê-se o romance proustiano como recurso sugestivamente reflexivo. As impressões detalhistas do real na forma do texto é que possibilita tal compreensão. Vejamos as duas primeiras posições de Antonio Candido.

\section{Antonio Candido contra Antonio Candido: ou duas versões de Proust}

Como muitos outros intelectuais brasileiros, Antonio Candido nos termos de Walnice Nogueira Galvão - foi um proustiano de vida inteira. Confidenciando a Célia Pedrosa em entrevista: ele considerava Marcel Proust seu escritor preferido. ${ }^{31}$ A confissão de Antonio Candido vinha acompanhada de uma elegante penitência estética e literária. Na sua capacidade sensível em ler expressões literárias através de feixes plurais sintetizados pelo quadro analítico rigoroso do erudito ele, na ocasião da entrevista a Célia Pedrosa comentava que suas primeiras leituras de Proust foram indelicadas para com o autor. Nosso crítico referia-se ao artigo que publicou no suplemento Notas de Crítica Literária do jornal

\footnotetext{
${ }^{28}$ GALVÃO, Walnice Nogueira. Op. cit., p. 16.

${ }^{29}$ WILLEMART, Philipe. Op. cit., p. 18.

30 Importa considerar aqui que de 1958 à publicação do ensaio Realidade e realismo (via Marcel Proust) nos anos 1980 (ou 1993, a data efetiva de publicação do texto ainda é incerta) o percurso da crítica e teoria literária de Candido passou por outras fases. Além da atividade de professor e intelectual público ele publicaria após suas primeiras leituras e comentários sobre Proust, Formação da literatura brasileira, O observador literário, Literatura e sociedade e Na sala de aula, dentre inúmeras outras. Não é exagero dizermos que essas obras de algum modo repercutiram no texto sobre o Em busca... dos anos 1980.

31 PEDROSA, Célia. Antonio Candido: a palavra empenhada. Rio de Janeiro: Editora da UFF, 1994, p. 135.
} 
Folha da Manhã em 1943 - condenando o Em busca... e seu autor. Nos decênios seguintes Antonio Candido voltaria a escrever sobre Proust; mas agora no Suplemento Literário do jornal O Estado de São Paulo: e com "uma atitude mais compreensiva"32. (Esta circunstância exprime uma mudança de orientação da crítica e da teoria literária de Antonio Candido, na qual Realidade e realismo (via Marcel Proust) pode ser lido, como um de seus momentos - talvez até de seu momento derradeiro como teórico da literatura.) Vejamos os referidos textos de 1943 e 1958.

Na década de 1940 as inquietações da sociedade brasileira repercutiam na crítica literária de Antonio Candido. ${ }^{33}$ Como não poderia deixar de ser o texto que escreve para o jornal Folha da Manhã sobre o escritor, que mesmo para os franceses, era tão controverso ${ }^{34}$, dada as inovações narrativas que propõe na composição de seu romance, expressaria a exaltação de nosso crítico com o andamento da cultura e da política no país. Escrevendo sobre a celebração de vinte anos da morte de Proust o texto de Antonio Candido estrutura-se em quatro instantes. Inicia nosso crítico com um discurso de louvor ao romance de Proust, pois este compele em seus leitores um desejo de presença, na qual nas palavras de Antonio Candido se exprimem na necessidade de sempre ter o Em busca... "à mão"35. Tal sentimento da presença de Proust experiencia-se como parte de nossa própria condição existencial de interação com os elementos sensíveis de (nossa) cultura humana. De modo que ao lermos o escritor da memória e do tempo - e todo o esplendor estético e composicional dos personagens que conformam estes - sentimos uma "sede" inesgotável ${ }^{36}$ de autocultivo através das páginas do romance. Mas após este brevíssimo encômio - Antonio Candido passa a uma crítica mais "sever[a] [em torno do] julgamento de valor" ${ }^{37}$ O passo que segue neste segundo instante, é o do tempo. Pois se nos tornamos angustiados pela presença de Proust em nossa experiência é porque sentimos que as coisas mortais - inclusive nós - são parte

\footnotetext{
32 ALMEIDA, Alexandre Bebiano. Um Proust mal lido, mas vivo? Nota sobre a recepção do romance proustiano nos decênios de 40 e 50. Lettres Françaises, n. 14, v. 2, 2013, p. 195.

${ }^{33}$ Ver sobre essa discussão: RAMASSOTE, Rodrigo Martins. Inquietudes da crítica literária de Antonio Candido. Tempo Social, n. 2, v. 23, pp. 41-70, 2011.

${ }_{34} \mathrm{O}$ caráter controvertido do romance de Proust expressou-se nas dificuldades que o autor encontrou para publicar seu primeiro volume, No caminho de Swann. A influência de André Gide sobre a maison Gallimard, em que tinha sido um dos seus diretores, fez com que eles não aceitassem Proust para publicação. A crítica francesa formada pelo romance do século XIX (Balzac, Stendhal, Vitor Hugo, Emile Zola), não poderia entender as inovações e a originalidade do Em busca do tempo perdido, bem como a dificuldade extrema em ler e compreender a obra. OLIVEIRA, Maria Marta L. P. Op. cit., pp. 57, 60, 63, 64 e 66.

${ }^{35}$ CANDIDO, Antonio. Notas de crítica literária - Vinte anos. Folha da Manhã, São Paulo, 04/03/1943, p. 5.

${ }^{36}$ Idem, ibidem, ibidem.

37 ALMEIDA, Alexandre Bebiano. Um Proust mal lido, mas vivo? Nota sobre a recepção do romance proustiano nos decênios de 40 e 50. Lettres Françaises, n. 14, v. 2, 2013, p. 195.
} 
inexorável de nossa existência. Quer dizer: o movimento de envelhecimento resultando na morte tem como essência o tempo que passa. E mesmo para o autor que teve o tempo como seu tema de vida e de impulso romanesco - isto foi decisivo. Como Cassandra de si mesmo Proust atormenta-se com "a fuga destruidora" 38 trazida pelo tempo: e foi contra este que ele escreveu seu Em busca do tempo perdido numa atitude narrativa angustiada e desesperadora. Para Antonio Candido, no entanto, de fato, o tempo proustiano havia passado. Ora, "Proust envelheceu; Proust passou; Proust não tem mais razão de ser" 39 em uma circunstância social na qual o que se exige dos autores e seus romances - são os sinais sublimados da cultura. ${ }^{40}$ Foi doloroso para nosso crítico, numa "atitude arriscada" 41 , atirar pedras ao seu "amor permanente". ${ }^{42}$ No entanto, em época de construção de valores morais exteriores, quer dizer num momento social em que aos escritores se exigia o claro e bem delineado compromisso com as questões públicas e comuns, Proust era o autor da "exploração emocional" 43 no pormenor: o esteta do detalhe mínimo. $\mathrm{O}$ romancista que buscou no mundo esotérico do espírito os fundamentos da estética: terminando por "hipertrofia[r]" 44 irrealisticamente todos seus sentimentos não era mais conveniente em sociedades que passavam por perturbações no seu processo política.

Com efeito, com essa pedra atirada ao seu "caro 'Temps Perdu'"45 Antonio Candido lamenta ter de lançar mais duas pedras a seu predileto romancista. No terceiro instante de seu texto de celebração ele "evidencia a paralisia da ação" 46 presente nas linhas do Em busca...; na medida em que se pedia aos escritores, críticos, cronistas - aos homens de cultura, apreciações morais sobre questões urgentes para o desenvolvimento da humanidade, "o movimento introspectivo" 47 composto por impressões sensíveis - ou pelas intermitências amorosas da alma - de Marcel Proust somente agravaria o "desajustamento das condições sociais" 48 naquelas circunstâncias. A outra pedra lançada por Antonio Candido, o último instante do seu texto, ao autor do Recherche tinha como intuito comentar a estetização da moral. (Ou o esteticismo dos problemas morais de um tempo candente por juízos de valor concernente aos melhores

\footnotetext{
${ }^{38}$ ALMEIDA, Alexandre Bebiano. Op. cit., p. 195.

${ }^{39}$ CANDIDO, Antonio. Op. cit., p.5.

${ }^{40}$ RAMASSOTE, Rodrigo Martins. Inquietudes da crítica literária de Antonio Candido. Tempo

Social, no 2, v. 23, 2011, p. 47.

${ }^{41}$ RAMASSOTE, Rodrigo Martins. Op. cit., p. 47.

${ }^{42}$ CANDIDO, Antonio. Op. cit., p.5.

${ }^{43}$ Idem, ibidem, ibidem.

${ }^{44} I d ., i b ., i b$.

${ }^{45} I d ., i b ., i b$.

${ }^{46} I d ., i b ., i b$.

${ }^{47} I d ., i b ., i b$.

${ }^{48} I d ., i b ., i b$.
} 
aspectos normativos para a vida em comunidade.) Como julgar questões primordiais para o convívio e a existência humana? Como desvelar os valores corretos para a boa relação amorosa? Diz nosso crítico:

Como julgar [a] sua [preferência] sexual? Segundo a tortura do ciúme que despertavam os seus prováveis encontros com Albertine, ou segundo a beleza incomparável cuja revelação não se daria sem ele? Em que plano, portanto, somos mais afetados pela ação de um ser; em que plano tem, realmente, mais valor, o resultado da conduta de um ser; - no plano imediato da vida, ou no essencial, daquela patrie intérieure, em que tudo, para Proust, se torna arquétipo de beleza eterna? O problema moral aí levantado - um dos mais graves de sua época e, quem sabe, também da nossa - é decisivo. Proust não o soluciona, deixando, por conseguinte, a possibilidade de uma moralidade baseada na estética - por assim dizer em que se operaria uma transmutação de todos os valores. Daí a minha segunda e, por agora, última pedra. Hoje em dia, tal atitude, além de perversa, é claramente perniciosa. A escolha já está feita e a evolução do homem não pode ser interpretada de dois modos. Todo aquele que sobrepuser a ordem estética à ordem ética estará condenado, porque esta inversão é um crime de lesahumanidade. ${ }^{49}$

Ora, com sua narrativa transbordando, incontrolavelmente, de esteticismo perante as questões de valores para uma vida (social) bem vivida Proust causa certo incômodo em Antonio Candido, já que no seu desdobramento o enredo do Em busca... termina como fenômeno cultural de prejuízo à humanidade. Assim, a ausência de "qualquer julgamento de valor" ético no romance proustiano era algo condenatório para nosso crítico.

Conquanto tenha permanecido preocupado com a articulação entre o social, o estético, o moral e cultural e o literário - com o passar do tempo "o crítico de rodapés cedeu lugar ao crítico de perfil universitário". 50 Julgando a partir de "um exame [mais] sério e refletido" 51 Candido altera sua leitura sobre a obra de Proust. Das resenhas e comentários que publica no fim da década de 1950 as abordagens começam a estimar o sentido literário do Em busca... - ao

\footnotetext{
${ }^{49} I d ., i b ., i b$.

50 ALMEIDA, Alexandre Bebiano. Um Proust mal lido, mas vivo? Nota sobre a recepção do romance proustiano nos decênios de 40 e 50. Lettres Françaises, n. 14, v. 2, 2013, p. 197.

${ }^{51}$ Idem, ibidem, ibidem.
} 
invés de "julgamentos tão severos" 52 acerca dos valores morais. Dentre estes textos consta a resenha que Antonio Candido escreveu para o Suplemento Literário do jornal $O$ Estado de São Paulo sobre o livro de George Painter sobre Proust. (Pode-se dizer que referido texto de recensão da obra do crítico inglês sobre Proust marca a passagem de nosso crítico até o Realidade e realismo (via Marcel Proust) de 1993.)

A resenha, significativamente elogiosa a Painter, destaca que o livro, uma biografia em dois volumes sobre Proust (o texto da resenha é só sobre o primeiro volume que cobre a vida do escritor até 1903), tem a proeza compreensiva de conseguir articular obra literária e mundo pessoal - sem incorrer em desequilíbrios na estrutura argumentativa. Com o intuito de observar, através dos materiais que dispõe, a vida do autor do Em busca..., Painter de acordo com Antonio Candido entende que aquela é o "caminho indispensável para compreender a obra". ${ }^{3} \mathrm{De}$ modo que o "mundo da obra" enquanto tal é preparado pela progressão da "narrativa da vida". 54 Assim, muitos dos "personagens" proustianos - Barão de Charlus, Dr. Cottard, Madame Verdurin, Odette, Swann "tem sempre base real" 55 na vida do escritor. O Em busca do tempo perdido, para Painter (e para Antonio Candido talvez?) é a composição verdadeira dos sentimentos de Proust para com a vida, ou seja, para com os indivíduos, os lugares, as cidades e as casas que formam aquela. Ele que amou mulheres mais velhas e "inacessíveis" 56 - as figurou, respectivamente, na Sra. de Guermantes e em Gilberte e Albertine. Com seus modelos reais de vida para compor o enredo literário do Em busca..., Antonio Candido diz (via Painter) que a obra proustiana está além da ficção, tornando-se no seu desenvolvimento narrativo "uma autobiografia criadora" ${ }^{57}$ É por isso que ele nos fala que a "originalidade" na biografia do crítico inglês está em que ele, com a posse dos materiais diversos sobre a vida do escritor ter conseguido demonstrar que com a composição estética de "elementos parciais" do mundo real Proust legou para a posteridade um esplendoroso e "prodigioso universo" literário 58 incomparável na história da arte romanesca. É nítida a "mudança de atitude do crítico"59 Antonio Candido diante de Proust, e do seu si mesmo passado. O crítico de 1958 começa a se distanciar, ou mesmo se opor, ao crítico de 1943. Neste aspecto particular, a oposição, por assim

\footnotetext{
$52 I d ., i b ., i b$.

${ }^{53}$ CANDIDO, Antonio. Marcel Proust, de George Painter. Suplemento Literário. O Estado de São Paulo, São Paulo, 11/06/1958, p. 2.

${ }^{54}$ Idem, ibidem, ibidem.

${ }^{5} I d ., i b ., i b$.

${ }^{56} I d ., i b ., i b$.

${ }^{57} I d ., i b ., i b$.

${ }^{58} I d ., i b ., i b$.

${ }^{59}$ ALMEIDA, Alexandre Bebiano. Op. cit., p. 198.
} 
dizer, do crítico de rodapé ao crítico dos estudos literários se completa, concernente ao Em busca..., com o ensaio: Realidade e realismo (via Marcel Proust) de 1993. Aqui o tempo para Antonio Candido representou o mesmo que para Proust; ele foi a justaposição contingente (social, política, cultural, acadêmica, estética, literária e de gosto pessoal) de experiências sucessivas de uma vida de então, que os possibilitou, às vezes sem que o percebessem, a conformação de suas respectivas e diversas autocompreensão existencial. Como dissemos há pouco, pode-se dizer que é partir do artigo de 1958 que nosso crítico lança as bases interpretativas, teóricas e conceituais, para ler Marcel Proust de maneira mais sugestiva, oferecendo-nos com ele as condições de uma teoria literária realista, e ao mesmo tempo (na forma enquanto tal) imaginativa, criativa, reflexiva e crítica. Passemos então ao andamento de nosso argumento principal.

\section{O Realismo como Teoria Literária}

Antonio Candido voltaria a escrever sobre seu escritor preferido em 1993. Nesse contexto ele já havia transitado definitivamente para a crítica literária - e sua expressão acadêmica, a teoria literária e a literatura comparada. Nesse percurso intelectual nosso crítico publicara trabalhos que hoje figuram como textos fundamentais não só para a disciplina de Letras, mas para aquilo que nas Ciências Sociais se convencionou chamar de pensamento político e social brasileiro. Assim, antes de chegar a Realidade e realismo (via Marcel Proust), Antonio Candido já tinha legado para a crítica literária brasileira: Formação da literatura brasileira, Crítica e sociologia e Dialética da malandragem. Malgrado estar inserido num conjunto de outros ensaios no volume Recortes e de seu aspecto despretensioso, o texto de 1993 sobre Marcel Proust revela e desvela muito do estilo de crítica de Antonio Candido. Ainda que com uma excessiva dicção sociológica em seu trabalho A passagem ao três a um, Leopoldo Waizbort é dos poucos a reconhecer o Realidade e realismo (via Marcel Proust) como representativo na conformação da crítica e teoria literária de Candido. Vejamos alguns andamentos argumentativos de Waizbort antes de reconstruirmos o ensaio de nosso crítico sobre Proust e interpretarmos seu sentido teórico.

Em A passagem ao três ao um afirma-se que com a "leitura dos estudos" 60 de George Lukács acerca do mundo real na literatura, Antonio Candido sedimentava sua compreensão sobre o "realismo e [a] realidade" 61 concernente ao problema da obra literária. Com efeito, o

\footnotetext{
${ }^{60}$ WAIZBORT, Leopoldo. A Passagem do Três ao Um. São Paulo. Cosac Naify, 2007, p. 176.

${ }^{61}$ Idem, ibidem, ibidem.
} 
recorte teórico que ira escrever "nos anos 1980" 62 sobre o escritor francês resulta; por um lado na aproximação ao teórico húngaro, como nos diz Waizbort, e por outro da própria concepção que Antonio Candido passaria a ter em relação ao Em busca do tempo perdido. Esta circunstância do seu percurso lhe seria repleta de significados, na medida em que com Marcel Proust - que desde há muito tinha "convívio amoroso"63 - o crítico possibilitava a si mesmo tratar de "quest[ões] teórica[s] decisiva[s]". ${ }^{64}$ De modo que o tema do realismo na literatura era factível de ser abordado, desde que pela via da narrativa proustiana. Ora, "o problema da realidade na obra literária não depende, no fundo, da aparência, das camadas superficiais da obra e do que ela apresenta, mas da profundidade". 65 Assim, é via a expressão das minudências narrativas de Proust, plenas de temporalidades composicionais, que Antonio Candido discute a questão do realismo. ${ }^{66}$ Diz Waizbort:

[nosso crítico] mobiliza [Proust] para uso próprio. [...] [O] problema da verossimilhança [e do realismo] ganha resposta no grau de convencimento extraordinário da narrativa proustiana, que embora 'crie' a realidade (dada a presença atuante da fantasia [...]), convence mais do que aquelas narrativas que buscam o sentimento da realidade exclusivamente mediante a 'função referencial' ${ }^{67}$

Que este último ponto da citação é um dos limites do ensaio $O$ realismo crítico hoje de George Lukács 68 - e que abordaremos através do Realidade e realismo (via Marcel Proust), é o que tentaremos argumentar,

$62 I d ., i b .$, ib.

${ }^{63} I d .$, ib., p. 247.

${ }^{64} I d ., i b ., i b$.

${ }^{6} I d .$, ib., p. 250.

${ }^{66} I d .$, ib., p. 251.

${ }^{67} I d .$, ib., p. 254.

${ }^{68}$ É certo como afirma o excelente estudo de Leopoldo Waizbort que Antonio Candido leu Lukács. Mas é discutível que o realismo como teoria da literatura tal como aparece no ensaio do crítico sobre Proust tenha como referência significativa o realismo lukacsiano. Marcel Proust (e James Joyce) como expressões originais do romance moderno de vanguarda que jamais foi aceito por George Lukács. Mesmo diferenciando os dois escritores e considerando que em Proust existiria certos elementos do mundo real, Lukács jamais se penitenciou por suas análises e comentários negativos sobre o autor do Recherche. Dos escritores do romance moderno de vanguarda Lukács, anos depois, somente concederia valor estético (e moral) a Kafka. Em troca de cartas com Carlos Nelson Coutinho, que na ocasião dizia estar preparando um livro sobre Proust e Kafka, o crítico húngaro disse que "no que diz respeito ao seu plano, êle me interessou muito. Que você veja em Proust e em Kafka o problema central, é algo inteiramente justo. É igualmente aconselhável, sobretudo no que diz respeito a Kafka, diferenciá-lo fortemente da literatura subsequente [de vanguarda]." Ver Carlos Nelson Coutinho - Introdução in: LUKÁCS, George. O realismo crítico hoje: abordagem de um dos problemas mais graves e fascinantes do nosso tempo: a relação entre o marxismo e as artes. Ed. Thesaurus: 1991, p. 12. 
brevemente, mais à frente. O que o autor de Formação da literatura brasileira diz no referido ensaio?

Logo no início do texto do nosso crítico podemos encontrar uma assertiva (mais a constituição de um problema para a teoria literária - do que uma afirmação propriamente dita) na qual a "verdade na literatura"69, mais precisamente sua "busca" está em organizar a disposição de configurar, esteticamente, "uma visão coerente e verossímil"70 dos detalhes do eu narrador. Quer dizer, na análise de Antonio Candido a exigência por equilibrar as oscilações entre a "particularidade [...] concreta [e a] abstração"71 imaginativa, torna-se "decisiva a maneira pela qual são tratad[as] as modalidades principais no Realismo". ${ }^{72} \mathrm{Em}$ seu horizonte interpretativo está a consideração do "Realismo [como] modalidade [...] moderna [...]"73 de literatura. ${ }^{74}$ No século XIX esta modalidade literária começaria (com Madame Bovary de Flaubert) a encontrar o espaço cultural necessário para iniciar sua trajetória narrativa. Mas neste contexto cultural prevaleciam ainda as formas estilísticas do realismo histórico (o romance histórico-social) e seus respectivos enredos romanescos - Balzac, Stendhal, Tolstoi, Vitor Hugo e Goethe expressam este instante da literatura ocidental. Esse estilo literário conforma "uma fidelidade documentária que privilegia a representação objetiva do momento presente da narrativa" 75 sem perder sua dimensão estética. E embora este estilo de romance tenha chegado até nós - e tenha, felizmente, seu espaço assegurado no cânone para falarmos com Harold Bloom -, no interior do "Realismo" há textos e obras que procuram aquele equilíbrio composicional de que fala Antonio Candido: na "razão oculta sob a aparência dos fatos narrados ou das coisas descritas". ${ }^{76} \mathrm{O}$ Em busca... é um louvor a este realismo (latente). De modo que os pressupostos deste realismo singular como teoria literária estão apresentados nas primeiras linhas do ensaio de Antonio Candido sobre Proust. Ora, para tornar mais expressivo, e pleno de sentido, a concepção de teoria literária (realista) de nosso crítico sugerimos avançar a noção de realismo presente em um dos ensaios de George Lukács sobre

${ }^{69}$ CANDIDO, Antonio. Realidade e realismo (via Marcel Proust). In: Recortes. Rio de Janeiro: Ouro sobre azul, 2004, p. 135. Utilizo aqui a edição da Ouro sobre azul, Rio de Janeiro 2004, mas o ensaio de Candido foi escrito e publicado entre os anos 1980 e 1990. No artigo de Alexandre Bebiano Almeida a que citamos mais acima a data de publicação é 1993, e no livro de Leopoldo Waizbort consta que o ensaio é dos anos 1980.

${ }^{70}$ Idem, ibidem, p. 135.

${ }^{71} I d ., i b ., i b$.

$72 I d ., i b ., i b$.

${ }^{73} I d ., i b ., i b$.

${ }^{74}$ Essa afirmação já seria suficiente para diferenciar as concepções de realismo de George Lukács e Antonio Candido.

${ }^{75} I d$., ib., ib.

${ }^{76} I d ., i b ., i b$. 
o tema; a saber, $O$ realismo crítico hoje: abordagem de um dos problemas mais graves e fascinantes do nosso tempo - a relação entre marxismo e as artes.

Neste ponto gostaria de oferecer a seguinte observação. Bem entendidas as coisas é preciso resguardar as complexas nuanças da crítica e da teoria literária de George Lukács com sua erudita concepção materialista de estética.77 Concepção essa que é constituída por obras como A alma e as formas, Teoria do romance, $\mathrm{O}$ romance histórico e Ensaios de literatura. Além destes de caráter mais geral e estético considere-se de importância decisiva na teórica literária lukacsiana os ensaios específicos sobre o realismo alemão e francês. Neste ponto mesmo divergindo do andamento argumentativo ${ }^{78}$ de Edu Teruki Otsuka concernente à amplitude do realismo em Lukács, sua observação em Lukács, realismo, experiência periférica (anotações de leitura) é conveniente e virtuosa ao comentar que a complexidade da crítica literária realista lukacsiana se deve a que nele o "realismo só se realiza de maneira plena na medida em que alcance a figuração do movimento da história ou mais precisamente, das forças motrizes da sociedade". ${ }^{79}$ Isto porque no andamento constitutivo de minha argumentação é mais do que claro que me aproprio de maneira crítica e tópica do ensaio de Lukács acerca do realismo na literatura, objetivando se distanciar dele e, junto com o Proust de Antonio Candido conformar a argumentação de uma teoria literária a partir do realismo (imaginativo) que não seja redutora à realidade concreta (documental), algo que ocorre por vezes com o crítico húngaro (a observação de Carlos Nelson Coutinho na Introdução ao ensaio de que iremos tratar a seguir é lapidar; de que nele, no Realismo crítico hoje, "não existe [...] nenhuma ruptura radical com o passado [de Lukács] [já que ele] continua criticando firmemente a tentativa de dissolução do realismo [...] pelas correntes vanguardistas" 80 na literatura). Isto posto, o crítico marxista comenta que: "o realismo dominou (durante

\footnotetext{
${ }^{77}$ Isso, obviamente, não exime Lukács das limitações, e podemos arriscar até equívocos, em sua leitura de Proust, Joyce e outros romancistas da vanguarda literária. O próprio fato de outros críticos marxistas e dialéticos, como Walter Benjamin, Theodor Adorno, Fredric Jameson e Roberto Schwarz, terem apreciado o romance moderno sugere os problemas de certos aspectos da abordagem estética lukacsiana aos textos de Marcel Proust, James Joyce e em menor medida de Franz Kafka.

${ }^{78} \mathrm{O}$ argumento de Edu Teruki Otsuka, ainda que ele deixe bem delineado o objetivo do seu texto, não considera a posição de recusa, até intransigente, de Lukács aos escritores da vanguarda literária - o que exprime por outro ângulo certos aspectos de sua concepção de literatura. Que de fato para ele ou é realista e grande, ou se não é decadente e sem valor estético o que é problemático inclusive da própria perspectiva da crítica literária histórico-materialista.

79 OTSUKA, Edu Teruki. Lukács, realismo, experiência periférica (anotações de leitura). Literatura e Sociedade, n. 13, v. 15, 2010, p. 38.

${ }^{80}$ COUTINHO, Carlos Nelson. Introdução. In: LUKÁCS, George. O realismo crítico hoje: abordagem de um dos problemas mais graves e fascinantes do nosso tempo - a relação entre marxismo e as artes. Brasília. Thesaurus, 1991 (1968), p. 9.
} 
a primeira metade do século XIX) [até] [18]48". ${ }^{81}$ Entretanto, "um tempo de águas baixas" 82 atingiu o esplendor do realismo literário. O que fez com que um movimento progressista de "revolta humanista" 83 tentasse resistir à nova época - através do "realismo burguês de hoje [que] é a continuação desse protesto".84 Evocando nomes conhecidos como Anatole France e Thomas Mann, o crítico húngaro procura, esperançoso, referências literárias e estéticas para sua Weltanschauung realista. Ele admite, no entanto, que na "vida literária de hoje [meados do século XX], [...] as tendências anti-realistas da vanguarda parecem predominar" 85 infelizmente. Num contexto de conturbação e conflagração mundial (de sedimentados interesses políticos) em que se exige "concepç[ões] [de] mundo" 86 que deem sentido à existência humana, era de se lamentar profundamente a vanguarda literária e seus "critérios de ordem formal: [como a] maneira de escrever, [a preocupação com a] técnica literária [e os] processos imediatos de realização". .87

Com efeito; Lukács está convencido do imperativo literário em contrapor Balzac, Stendhal, Goethe, Tolstoi e Vitor Hugo a James Joyce, Marcel Proust, Kafka e Beckett: enquanto naqueles o realismo (moral) é expressado por personagens que lançam-se ao mundo "histórico-social com todas as categorias [narrativas] que dele dependem [e que são] inseparável [...] de sua realidade efetiva, do seu ser em si" 88 , de sorte a conseguirem pelo percurso literário dos personagens e por vezes do próprio narrador dizerem algo sobre "as relações humanas" repleto de "juízos de valor" 89 ; estes escrevem unicamente do "ponto de vista formalista [...] [na qual procuram afirmar] a dissolução da personalidade [...] [a] dissolução do homem e [a] dissolução do mundo". ${ }^{90}$ Assim, a preocupação da teoria realista de Lukács é que no enredo da vanguarda literária a "possibilidade concreta" fica esterilizada - e a ruptura estética "dos laços existentes entre exterior e o interior" 91 ganha projeção em detrimento do sentido ético-literário. E mais: lançando com veemência sua crítica moral à estética modernista ele acusa tais escritores de uma "fuga para o patológico, [...] puramente abstrato e vazio, [eles] só condena $[\mathrm{m}]$ o real (ao qual pretendem escapar) em termos sumários e

\footnotetext{
${ }^{81}$ LUKÁCS, George. O realismo crítico hoje: abordagem de um dos problemas mais graves e fascinantes do nosso tempo - a relação entre marxismo e as artes. Brasília. Thesaurus, 1991, p. 31.

82 Idem, ibidem, ibidem.

${ }^{83} I d$., ib., ib.

${ }^{84} I d ., i b ., i b$.

${ }^{85} I d .$, ib., p. 33.

${ }^{86} I d ., i b ., i b$.

${ }^{87} I d ., i b ., i b$.

${ }^{88} I d ., i b .$, p. 37.

${ }^{89} I d .$, ib., pp. 36 e 37.

${ }^{90} I d .$, ib., pp. 34, 44 e 47.

${ }^{91} I d$. ib., p. 49.
} 
gerais e não [dão] lugar a qualquer crítica concreta da realidade efetiva". ${ }^{2}$ É a própria fuga para o patológico e para o vazio que orienta, na leitura de Lukács, as obras de Joyce, Kafka, Beckett, Proust e Musil. Dessa forma, literatura para ele significa a realidade (documental) plasmada na estrutura composicional e no enredo da obra, de tal modo que pela configuração concreta do real posta com precisão referencial na tessitura do romance se possa compreender as angústias da humanidade num tempo de guerra e crises sociais. Uma teoria (moral) da literatura para George Lukács importa mais que a forma literária enquanto tal: o crítico húngaro desde os anos 1930 compreendia o romance muito além de técnicas peculiares e inovadoras da forma de narrar, às obras se tornava necessário como caráter distintivo que elas promovessem a "mais dura crítica [a]o mundo que se oferecia à sua representação". ${ }^{93}$ Sobre Marcel Proust, especificamente, um dos escritores mais identificados com a vanguarda literária, $O$ realismo crítico é intransigente no seu comentário: o que há é somente "o idealismo subjetivo [...] Para ele [Proust], o tempo propriamente dito, o tempo autêntico, não é mais do que o tempo puramente subjetivo, o da experiência vivida, completamente desligado do mundo real ou objetivo" . ${ }^{94}$ A condenação de Lukács ao modernismo literário exprime, indubitavelmente, que para ele a obra romanesca digna de ser lida e resguardada como verdade do humano: são aquelas nas quais a narrativa se desenvolve assentada, impreterivelmente, no realismo histórico e social. E este é para o crítico húngaro demonstrado quando o escritor modela seus personagens - o narrador e sua epopeia, o enredo composicional - com a "realidade efetiva [e] uma profunda concepção do mundo" ${ }^{95}$ Documentos morais para uma vida ética - é o que exige a teoria literária lukacsiana em $O$ realismo crítico hoje.

A modalidade de realismo na literatura para Antonio Candido tem outro sentido. Ao contrário de George Lukács, e via ao escritor que ele mais identificou com o antirrealismo, Proust, nosso crítico permite-nos vislumbrar um realismo como teoria literária que pode ser imaginativo e no mesmo passo generoso, esteticamente, enquanto forma literária. Mas isto é possível, literariamente factível por assim dizer, desde que a "visão realista" pressuponha; "a multiplicação do pormenor, [...] a sua especifi-

\footnotetext{
${ }^{2} I d .$, ib., p. 51.

${ }^{93}$ LUKÁCS, George. Op. cit., p. 65. Na sequência do argumento tratando das artes plásticas Lukács diz que: "basta evocar a história da arte medieval para verificar, por exemplo, em Giotto, de que maneira esse sentimento do mundo terreno, apesar da sobrevivência de temas religiosos, se sobrepõe de maneira cada vez mais decisiva ao alegorismo original" (grifo meu), $\mathrm{p}$ 66.

${ }_{94}$ Idem, ibidem, p. 63.

${ }^{95}$ LUKÁCS, George. Op. cit., p. 198.
} 
cação progressiva e o registro de suas alterações no tempo" ${ }^{96}$ Quem não for além do Lukács de $O$ realismo crítico hoje terá pouca possibilidade de compreender que o Em busca... é dotado de material literário para o realismo proposto por Antonio Candido. Voltando aos pressupostos do realismo via Marcel Proust ele se encontra, em oposição ao realismo lukacsiano, lá onde a "existência do objeto ficcional" 97 pode adquirir confiança plena nas particularidades estilhaçadas na composição da obra; mas que no mesmo movimento narrativo estabelece a "qualificação do seu sentido específico e a adequação [coerente e ritmada] das partes" ${ }^{98}$ Valendo-se de uma passagem do volume $O$ tempo redescoberto, o último do Em busca do tempo perdido Antonio Candido constrói o andamento de seu realismo literário, e imaginativo. Ele cita Proust ${ }^{99}$ :
O sol
O sol/ iluminava
O sol/ iluminava/ até meia altura
O sol/ iluminava/ até meia altura/ um renque de árvores
O sol/ iluminava/ até meia altura/ um renque de árvores/ que margeava a estrada de ferro.

Note-se no trecho recortado que a composição literária articula no instante da constituição narrativa, nexos sucessivos de partículas, altamente, pormenorizadas do real. De sorte que é este efeito de detalhamento na forma romanesca que traz dinâmica imaginativa ao real - e que no mesmo passo adquire sentido estético uma vez que é na "duração [...] históri[ca] [presente] no cerne da representação da realidade"100 que o "efeito do tempo sobre" as minudências"101 não os deixa evadir-se. Assim, para estilizar minha interpretação, importa, neste contexto propormos a seguinte questão: por que o crítico elegeu, precisamente, uma passagem do volume sete, o último do Em busca..., em meio a tantas passagens significativas que irrompem no romance? Passagens como a Madeleine mergulhada no chá no volume um, a descrições do salão dos Guermantes no volume três, o passeio de Andreé e Albertine pela praia de Balbec no volume dois, o flerte homossexual entre o Sr. Charlus e Jupien espiado (vouyeristicamente) por Marcel (o narrador do Em busca...) em Sodoma e Gomorra, o volume quarto, e as intermitências do coração no narrador afetado pelo temor da perda de Albertine nos

\footnotetext{
${ }^{96}$ CANDIDO, Antonio. Realidade e realismo (via Marcel Proust). In: Recortes. Rio de Janeiro: Ouro sobre azul, 2004, p. 136.

${ }^{97}$ Idem, ibidem, ibidem.

${ }^{98} I d ., i b ., i b$.

${ }^{99} I d ., i b ., i b$.

${ }^{100} I d ., i b ., i b$.

101 Id., ib., p. 137.
} 
volumes cinco e seis. Ora, Antonio Candido como nos diz Walnice Nogueira Galvão foi um proustiano de vida toda e Marcel Proust, por conseguinte, seu escritor predileto - nosso crítico construiu ao longo de "décadas de convívio amoroso"102 com o escritor da memória e do tempo. E conhecia passagens - estas a que nos referimos inclusive infindáveis do Em busca do tempo perdido que poderiam expressar sua teoria literária realista (e imaginativa). A indicação para a análise de $O$ tempo redescoberto não era fortuita. (É neste volume último que o ápice do teor romanesco é alcançado. Nele, Marcel dá sentido às oscilações que os pormenores da sua existência o vão afetando no transcurso do tempo. Se nos outros volumes encontramos o narrador-personagem diante de fios - reais - de uma vida intermitente que se espalham pela estrutura mesma da narrativa, e que na sua face imediata incita ao leitor a percepção de um suposto (e equivocado) subjetivismo estéril; em $O$ tempo redescoberto o detalhamento dado pela subjetividade de Marcel adquire significado pleno. Pois é na permanência do tempo - dado pela obra de arte - , e enquanto fenômeno sensível da memória, que a multiplicidade de eventos disseminados na trajetória do narrador-personagem expressam o andamento realístico da obra literária proustiana. E o volume escolhido por Antonio Candido não só satisfaz a estrutura de sentidos do romance como texto unitário - mas desfaz, definitivamente, o suposto subjetivismo estilhaçado pelos momentos de interação afetiva de Marcel ao longo do seu percurso. O tempo redescoberto: desvela num olhar amoroso para trás qual é o sentido de uma vida vivida na dinâmica particular da realidade existencial. Por outras palavras, mesmo uma (ou diversas) realidade criada, imagética e alegoricamente, é alentadora para se perceber o sentido de uma vivencia de então e nos afetar para a experiência presente e talvez futura. Assim é que Marcel pode dizer questionando-se a si mesmo; "como as individualidades (humanas ou não) se comporiam neste livro de impressões múltiplas, as quais provocadas por muitas [pessoas], muitas igrejas, muitas sonatas, serviriam para constituir uma única sonata, uma única igreja, uma única [pessoa] [...] Sim, a esta obra, a noção do Tempo, que acabava de adquirir, me dizia [que era] chegada a hora de consagrar-me [à obra] [...] Obra tal como há pouco a concebera na biblioteca [na] análise em profundidade das impressões [...] recriadas pela memória". ${ }^{103}$ Lamentamos Lukács pelos inconvenientes interpretativos de seu realismo plano e documental. Mas voltemos, sem mais, a Antonio Candido - felizmente.)

Nosso crítico a partir de $O$ tempo redescoberto argumenta que as "alterações trazidas ao pormenor pelo tempo"104 são capazes de

\footnotetext{
102 WAIZBORT, Leopoldo. A Passagem do Três ao Um. São Paulo: Cosac naify, 2007, p. 247. 103 PROUST, Marcel. O Tempo Redescoberto. Porto Alegre: Globo, 1998, p. 281.

${ }^{104}$ CANDIDO, Antonio. Op. cit., p. 136.
} 
"introduzir duração [...] no cerne da representação da realidade". ${ }^{105}$ Seguindo em sua crítica, Antonio Candido interpreta que na literatura proustiana o sentido real mais alto se revela na "chuva de pormenores formada pelo [...] livro". 106 De modo que em "o sol", "o sol/iluminava/até meia altura" e "até meia altura/um renque de árvores/que margeava a estrada de ferro", a ficcionalidade narrativa apresenta seu realismo imaginativo, lá onde cada "detalhe" se fez "generalização que [...] transfigura"107 os feixes de, supostos, subjetivismos: dando a eles elementos literários plenos de sentido narrativo. É que Marcel Proust tinha "uma teoria não realista da realidade, que acabava numa espécie de transrealismo, literária [...] [e esteticamente] mais convincente do que o Realismo referencial" $108 \mathrm{e} / \mathrm{ou}$ documental, ou ainda se se preferir social e moral como queria Lukács. Neste aspecto o tema da interioridade e exterioridade no Em busca... aflora na crítica de Antonio Candido - e ao lado dele o problema da articulação composicional entre estrutura e processo.

Deste modo, Realidade e realismo (via Marcel Proust) trata com sensibilidade analítica e esmero o problema dos mundos interior e exterior no romance proustiano. Com essa abordagem, Antonio Candido constrói mais andamentos para estabelecer sua teoria realista (e imaginativa) da obra literária. Pois é na interioridade de Marcel que as impressões do detalhe se transfiguram em realidade expressiva. ${ }^{109}$ É como se Antonio Candido estivesse dizendo (contra a leitura apressada documental - da crítica lukacsiana ao suposto subjetivismo de Proust) que é lá onde o narrador-personagem do Em busca... se encontra mais consigo mesmo através da multiplicidade de eventos dispersos na memória, na sua vida de então, que se estabelece o realismo literário do escritor francês. Neste aspecto na qual trata a questão, Antonio Candido (via Proust) procura constituir uma interpretação realista na literatura sem que esta fique circunscrita, exclusivamente, ao espaço da realidade concreta da sociedade. Aqui, nos termos do crítico da ideia de literatura, crítica e teoria, estes deixam de ser o espaço estético do autocultivo (como possibilidade de ação no mundo), para se tornarem: quadros estreitos de referência documental do mundo (estático) para orientações moralizantes de questões da vida e da política. Mas nosso crítico constrói outro realismo através do Em busca do tempo perdido. Com efeito, é na articulação de certas modulações estilizadas e imagéticas do mundo exterior com a dispersão das impressões detalhadas da realidade interior (no narrador-

\footnotetext{
105 Idem, ibidem, p. 136.

106 Id., ib., p. 137.

${ }^{107} I d ., i b ., i b$.

108 Id., ib., ib.

${ }^{109}$ Id., ib., ib.
} 
personagem) que se permite à "linha expressiva da representação ficcional"110 obter tessitura narrativa equilibrada e plena de significados literários e estéticos. Portanto, o Em busca... concede ao pormenor interior, beleza composicional. Ora o que "Proust delineia" para Antonio Candido é "uma teoria que pressupõe [...] o tratamento simultâneo da estrutura e do processo, ou, nos termos da presente discussão, do pormenor integrado em configurações [exteriores] e expressivas".111 O que este último ponto pretende?

Pretende-se, com ele, instituir o realismo como teoria literária imaginativa. Ou numa outra formulação, mas com o mesmo sentido; quer-se com isso constituir a imaginação no realismo como teoria literária "dinâmica e poliédrica". 112 Conforma-se assim, a criação imaginativa da existência real na articulação dos dois momentos literários - ou o que Antonio Candido nomeia de "síntese [inventiva] de uma visão integra[da]". ${ }^{113}$ De modo que nos momentos singulares que irrompem nas intermitências contingentes do percurso do narrador-personagem, Marcel, a significância literária destes possa adquirir vida na composição estético-memorialística da obra pensada como um todo. Nosso crítico pode dizer com isso que: "há, portanto, [no Em busca do tempo perdido] vinculações ocultas que ligam os pormenores e compõem uma espécie de modelo permanente no meio da fuga do tempo. Elas seriam a base do projeto de Proust, ao provarem que é possível a luta da arte contra a dissolução operada por ele". ${ }^{114}$ A compreensão subjacente no ensaio de Antonio Candido, é que a realidade na obra literária só pode ser plenamente satisfeita (na modernidade cultural) se o arco do sentido histórico da arte estabelecer como pressuposto inarredável o "particular relativo" 115 e o pontilhismo profundo e ao mesmo tempo descontínuo da trajetória dos personagens. Por outras palavras; foi na obra de Proust que Antonio Candido descobriu que "é na relação dinâmica entre tempo e modelo que os detalhes adquirem o verdadeiro sentido". ${ }^{116}$ Como isto se dá por fim diante da teoria literária de Lukács? Se o realismo documental, tal como o apresentamos por meio de $O$ realismo crítico hoje de George Lukács, perde-se na superficialidade estática e inerte da realidade social objetiva, que se plasma, estética e diretamente, no conteúdo do romance perdendo com isso todo o significado composicional da obra literária, o realismo que nosso crítico toma partido é aquele na qual se tenciona narrar a existência artística como impressão da vida de "muitas maneiras,

\footnotetext{
110 Id., ib., ib.

111 Id., ib., pp. 137 e 138.

112 Id., ib., p. 140.

113 Id., ib., p. 141.

$114 I d ., i b ., i b$.

115 Id., ib., ib.

116 Id., ib., p. 142.
} 
recomeça[ndo] de vários ângulos, [vendo] o objeto ou a pessoa de vários modos, em vários níveis, lugares e momentos, [e] só aceitando a impressão como índice ou sinal". ${ }^{117}$ Com efeito, o romance de Proust lido enquanto conformação da subjetividade oscilante, expressiva e detalhada do narrador no plano mesmo da obra de arte, possibilita a apreensão literária e estética da realidade como elemento constitutivo do jogo narrativo do estrutural no processo - a processualidade estruturada. É isto que permite Antonio Candido ir além do realismo documental, apático e superficial. E com isso ele nos oferece um realismo como teoria literária em que ao privilegiar o pormenor nos seus modos diversos de impressão no narrador-personagem (o processo) num contexto de "generalidade"118 (a estrutura) e composição integrativa (estética, artística, sensível, amorosa, temporal e cultural) dotar o leitor de autocultivo imaginativo, transcendente e crítico da sociedade.

\section{Breves Considerações Finais}

Com algumas imperfeições na exposição, bem como certos exageros na forma de construir o presente texto levando, assim, a equívocos de linguagem e de interpretação; busquei apresentar um ensaio que muito diz da crítica literária de Antonio Candido e das leituras que o formou ao longo de seu percurso como intelectual que devotou sua vida à literatura e à vida pública (sobretudo à dos de baixo). Marcel Proust foi o escritor, a tomar o que nos diz Walnice Nogueira Galvão, Célia Pedrosa, Alexandre Bebiano Almeida e Leopoldo Waizbort, que mereceu o amor de Antonio Candido por toda sua existência. E foi através do autor do Em busca do tempo perdido que nosso crítico, no breve, porém denso ensaio que devotou a ele, pode dispor a nós, elementos para formularmos uma teoria literária realista e imaginativa. Observando a estrutura e o processo pelo qual Proust compôs sua obra, nosso crítico oferece alento para aqueles que se preocupam com a uma crítica literária, que possa ser ao mesmo tempo estética e social.

\footnotetext{
Ronaldo Tadeu de Souza possui graduação em Ciências Sociais pela Pontifícia Universidade Católica de São Paulo (2004), mestrado em Ciências Sociais também pela Pontifícia Universidade Católica de São Paulo (Área de Concentração - Política) (2008) e doutorado na Área de Teoria Política no Departamento de Ciência Política da Universidade de São Paulo USP (2017). Foi professor de sociologia do direito no Centro Universitário Unifieo de 2009 a 2013 e de teoria política no Curso de Extensão da Fundação Escola de Sociologia e Política de São Paulo em 2017. Minhas pesquisas estão concentradas em: teoria política moderna e contemporânea com enfase em Hannah Arendt, Leo Strauss, Giorgio Agamben e Seyla Benhabib; teoria das ciências humanas, teoria democrática contemporânea com foco em Joseph Schumpeter e pensamento político e social brasileiro. Contato: ronaldolais@yahoo.com.br
}

${ }^{117} I d .$, ib., p. 140.

${ }^{118} I d .$, ib., p. 141. 